\title{
Innovative Development of the University as a Mandatory Condition for the Formation of National Elites in the Process of Training for High-Tech Industries
}

\section{Viktoria Myasoedova}

\author{
Systems Institute of Economics, Management and International Law \\ Moscow region, Mytischi, Kolpakov str. 2A, 141002, Russia; Email: dbrf2408@yandex.ru
}

Nataliya Lebedeva

K.G. Razumovsky Moscow State University of technologies and management (The First Cossack University) MoscowZemljanoj Val st. 73, 109004, Russian; Email: Inataleks@mail.ru

\section{Doi:10.5901/mjss.2016.v7n1p312}

\section{Abstract}

The article presents the analysis of algorithms of formation of the youth of the elite at the present stage of development of Russia and substantiates the relationship of these processes with the innovative development of higher education, as a mandatory condition for the formation of national elites in the process of training for high-tech industries. Basic cause-andeffect relationship of an institute's mission of youth and its further promotion to representative bodies of state power, local selfgovernment, political parties on the basis of the higher education sector. Updated the impact of the modern state with the innovation economy, on the growth of human capital and technology development, taking into account globalization and the trend of internationalization of various spheres, represented by the role of education in this process. As the main research methods used: a logical analysis, modeling, process approach, benchmarking. The results of the study were: to develop the basic characteristics of reference for public policies which have a positive impact on recruiting youth elite; the formulation of conditions of innovative development of higher education and the key factors in the successful accomplishment of the universities in the training of elite personnel for high-tech sectors of the economy; development of models of processes of formation of the youth of the elite, able to ensure the development of high-tech sectors within higher education institutions.

Keywords: elite youth, human capital, innovation development of the university, preparation of highly qualified specialists , state policy in the sphere of education.

\section{Introduction}

In the twenty-first century globalization contributes to the emergence of a new type of social differentiation, leading to a worsening of the gap between countries, creating technological innovation and exporting them around the world, and those who are forced to blindly use these developments. (Kemple and Mawani, 2009)

These differences in the quality of human capital, primarily affect youth resources because their incentives, investment in its development is able to overcome the intellectual and technological backwardness. The processes of globalization pose a threat to national identity, cultural and civilizational diversity of the world, individual freedom, cause tensions in inter-civilizational relations. (Shuman and Scott, 1989). However, globalization can expand horizons for mutual data communications, convergence of cultures, their dialogue, to open new opportunities for joint intellectual, industrial and scientific activity.

The development of a strong, modern state formation in it of the innovation economy, built on the growth of human capital and technology development, as occurs in the context of globalization and the trend of internationalization of various spheres. Education in this process is the underlying, and acts as a platform for the synthesis of different areas that allow you to create a new elite (or to provide a reserve for the reproduction of the current elite), the quality of which will determine, in turn, the efficiency of the country's development. Therefore, any public policy that aims to centripetal development, i.e. qualitative and fruitful cooperation between the interested authors to ensure the common good of its citizens, needs to focus on youth trends and bring to the expert, analytical and project work of young specialists in the sphere of political, legal, managerial, economic relations. The consequences of this approach can Express new fields, methods, steps that may be used by top officials of the state to ensure the rule of law and the progressive development of society. So, the Modern society of today, according to Anthony Giddens is determined that it is necessary the existence 
of a reflexive system for social development, which you can trust in abstract systems, i.e. networks of excellence (Giddens, 1990).

In accordance with the Concept of elite pluralism J. Schumpeter, the political elite should be in the post-industrial society the part of the intellectual layer of people which is interested in social development and are ready to apply their knowledge and practical competence for the common good. He noted that "the principle of meritocracy needs to get into the universities, business, government. A society that does not have their best men at the head of its leading institutions, there are sociological and moral absurdity" (Bell, 1973). This approach is very expressive and should be fully implemented by the state. This will allow for upward vertical social mobility regional youth elite on "political Olympus" state and non-state political institutions.

One of the Russian scientists who study the field of national and federal relations V.V. Gaiduk said that the image of the Federation can be formed, including on what the elite are represented in it: "But now is a different time, a time of change. In modern conditions the political image of the Federation - is not only investing in the region (which is certainly not unimportant), but also the opportunity to compete with other regions in the economic, social and cultural spheres of public life". (Gaiduk, 2011) Thus, the Graduate School serves as a key element in the formation of elite cadres of the national economy. And the innovative development of higher education and the country's leading universities - the key to well-being and prosperity of the nation.

The optimal model, in which the young leader has the ability to replenish the talent pool of highly qualified professionals, government institutions, the political and administrative sphere, is the observance of the principles of good lobbying their own projects, ideas, interests, are interested in the existing elite. To do this, you must have high-quality fundamental education is extremely positive indicators of success of projects, irreproachable biography, and stylish modern image of the young leader (it is not necessary to relate this point with only external data the emotional and sensual nature). Under the image is meant a set of social reference points (in particular, formed in the learning process in higher education), followed by a young man seeking to take its rightful place in the niche of intellectual strata of society, responsible for qualitative changes in the name of innovation in Russian society. Consequently, the elite needed concept in which they: "With the most accurate knowledge of the electoral activity, demands and trends, political technologies have broad map features in the creation and promotion of a political product as a whole set of elements, taken separately candidate's behavior, appearance Biography, program of action and other features that justify the choice of the people and their trust ". (Lukyantsev, 2014)

\section{Methodology}

One of the forms of interdisciplinary communication between the leaders of the modern "elite" of the country and youth communities is the higher education system, which is why the process of formation of young elite distinctively observed in higher education institutions and the higher education system is a key element in the training of elite personnel for the real economy. Today, the importance of higher education is also caused by the fact that in the framework of the devaluation of the previous identity and mass "search for identity" High School serves, in our opinion, the only segment of the state and society, which preserves the cultural and scientific traditions.

Thus, the most important task of higher education in Russia is to maintain its competitive advantage, provided that the adaptation to the new global training system. This problem, as a consequence of globalization and the ratification of the Bologna Agreement by the Russian Federation in 2006, arose in connection with the pursuit of the world system of education for standardization, in creation of a single-tier system that will blur the boundaries between countries and institutions. This transformation requires not only increasing competitiveness. Russian universities due to their innovative development, but the restructuring process intrahigh with their focus on openness, transparency and efficiency.

The activity of the modern, open "international" university must be subordinated to a single goal - the preparation of highly qualified specialists and research activities, which are a priority in all socio-economic formations, which provides a stable environment for both social self-identity and self-identification of students as Intellectual elite group.

High school is the social institution that ensures the development of high-tech sectors of the economy by preparing highly qualified personnel and the national elite, able to solve strategic tasks of innovative development of the country. Therefore, identifying the key success factors of innovative development of the University and the modeling of processes of formation of the youth of the elite, able to ensure the development of high-tech sectors within higher educational institutions are one of the methods to solve the abovementioned problems. 


\section{Main Part}

Innovative development of the higher school and its separate elements - higher education institutions is an essential condition for national development, improving living standards and the competitiveness of the national economy on the world stage. According to the results of analysis studies revealed that the innovation development of higher education is possible, if certain conditions, such as:

- rapid technology development and determines the value of the manufacturer and the carrier of the knowledge of the person;

- the dominant human capital, creativity, knowledge and intelligence in society, the changing nature of human activity;

- care on the backburner material factors and the priority of non-material values - empowerment, a sense of satisfaction from the work done, the possibility of contacts with people, social and collective recognition of certain achievements.

Such socio-cultural transformations cause a new type of social stratification, the main criteria of which are the level of professionalism, educational qualification (primarily special education). In the stratified structure of modern society is allocated a qualitatively new strategy, the social importance of which is based on the level of intelligence of its representatives. In society there are people whose social status, material well-being is defined as the result of their creative self, the use of intellectual resources, knowledge, professional competencies. Initially acting as the periphery, the stratum of intellectuals gradually occupies the dominant position in the system of industrial relations and in the social space, and in the field of public administration, acquires sustainable features and essential characteristics, and is a powerful force able to influence the most important positions of social and state development.

On the other hand, in modern society, along with the emergence of a new group, generating tendencies of postindustrial transit continue to operate quite powerful determinants of industrial society, resulting in a system of social contradictions that arise in the plane of the interactions of the new strata to the state and society as a whole and in the relationship with traditional classes, strata and social groups of the industrial society.

Therefore, the process of innovative development of the university should be focused on achieving the main goals of higher education, the preparation of national elites (highly qualified personnel for the national economy).

Given the socio-political and economic trends, key success factors of innovative development of the University and perform the tasks of preparing elite personnel for high-tech sectors are:

1) Monitoring of internal and external environment of the university.

Monitoring system implies the existence of methods and tools to collect and analyses information on the state of the external and internal environment of the University, which will allow you to make timely management decisions, contributing to the adaptation of internal processes and the strategy of innovative development of educational institutions in accordance with the trends of the global environment.

The system of monitoring of the external environment should not be limited to the collection and analysis of information about the internal state of the local market (within a specific region) or national market. It must take into account relevant global trends.

The system of monitoring of the internal environment involves a holistic, multidimensional approach, as well as a comprehensive study of intra-organizational processes (Lebedeva, 2014);

2) Staffing the business processes of the university.

Staffing covers all the processes of an educational institution related to the formation and realization of strategy of human resource management. Key elements of staffing are (figure 1):

- ensuring the university's human capital professionals, capable of making decisions in terms of strategic instability, tension and uncertainty ;

- development of investment priorities and programs of staff development;

- stimulation of change and the formation of adaptive behavior of personnel to work in unstable conditions of the external environment;

- formation of corporate culture and corporate climate that meets the needs of the HR policy and strategy of the educational organization. 


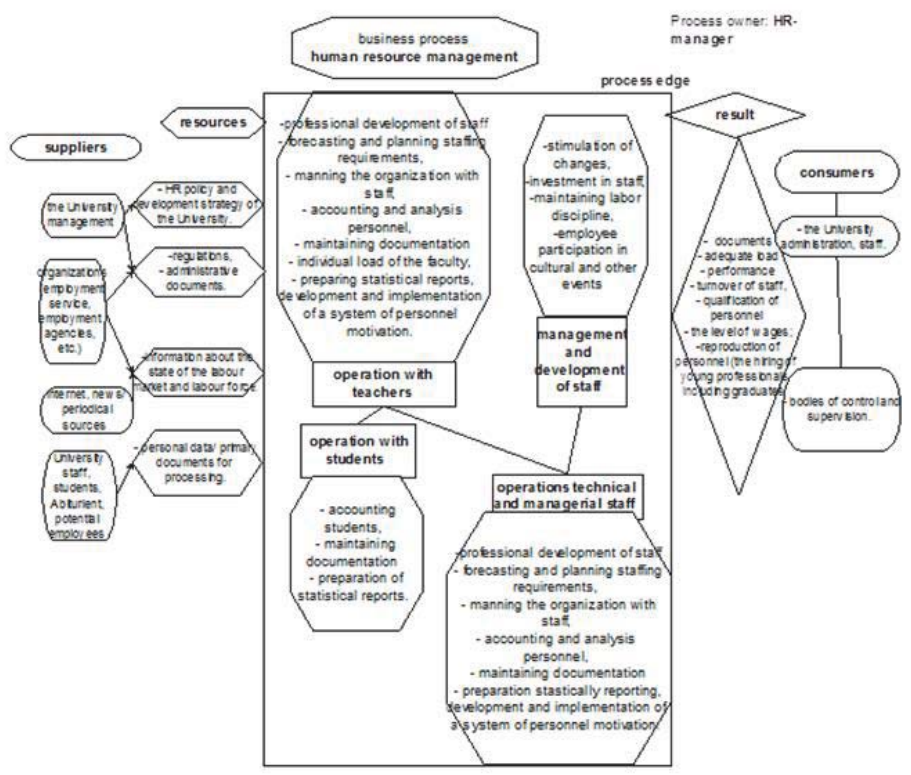

Figure 1. The model of the business process "Staffing and personnel management"

3) National and international policy in the field of education.

Of course, the optimal model in which the representative of the youth elite has the ability to replenish the personnel reserve of high-tech sectors of the economy and state institutions, the political-administrative sphere, is the observance of the principles of qualitative lobbying their own projects, ideas and interests that will be of interest to existing, as of today, the political elite.

In search of new methods, forms of interaction between state institutions and youth elites to further their recruitment in the highest echelons of power possible coordination of overall development, with signs of deliberative democracy and its main characteristics. For General development, in our opinion, it is the democratic deliberate, today's generation of new intellectual elite, can cause the greatest sympathy. Denote that in the development of the theory of deliberative (deliberative) democracy has made a significant contribution to the representative of the Frankfurt school of political science Yu. Habermas (Jurgen Hubermas), which introduced the concept of "publicity" (Öffentlichkeit) and the political variables of the new generation. Such "publicity" should be expressed, according to the thinker, in search of new forms of democratic procedures. The extremely bright Habermas presents this by transforming private interests in public, this directly contributes to the field of publicity, during which the transition occurs from the participants of communication (Habermas, 1989). Overall, in considering the question of implementation of the projects and ideas of youth leaders, the authors of which subsequently have the opportunity to improve their social status by becoming a leader at the Federal level, it is necessary to take into account the fact that any social action that bears a rational nature, has the ability to benefit, both for the author of the project and for the entire community.

The main characteristics of reference for public policies which have a positive impact on the recruitment of regional youth political leaders. First, it is efficiently formed the theoretical and empirical assumptions, objectives, expected results from government and non-government institutes policies that support the implementation of socially significant initiatives of the intellectual youth of the elite of the new, post-industrial society. (Kymlicka, 1990) This may manifest in the following forms:

- provision of grant support for projects and ideas. This system, as it is known, has a number of advantages for both the grantor and the grantee. To obtain reliable information and high quality result on the requested service / order to perform certain types of work on social development of public institutions. For the latter is the formation of wide interest both in his personal person, a team, and in promoting their own product at the regional and Federal level.

- subsidization of innovative industries, aimed at import substitution. 
Secondly, the formation in the public mind the idea that youth elite have all the opportunities, resources, and effort to build brand new guidelines, which encourage the bulk of citizens to transform their own lives and society in General. (Commissariat Général du Plan, 1996) This situation would be the ideal option for stakeholders in the successful development of the state and all its institutions benefiting the citizens. This is possible with qualitative recruitment, both at the Federal level elites from youth environment and regional.

The above circumstances stipulate the importance of scientific and theoretical understanding of the development patterns of higher education institutions as "incubators" of the national elite. Huge internal capacity of the higher school determines the need for a definition of the methodological apparatus, based on the formation of the national elitokratiya that actualizes the study of the problems of the use of intellectual and socio-cultural potential of the University in the context of selection of the intellectual elite, capable to meet the challenges of the postindustrial transit. Element of the methodological apparatus may act as a "model of innovative development of the University" focused on the development of higher education as a strategic state institute.

The higher education system is designed to meet the needs of society in specialists who are able to compete in the labour market, able to solve problems of reproduction of goods, services, knowledge, behavior patterns, values, spiritual life. Accordingly, higher education is understood as the unity of two interrelated processes: education and training, and the essence of the first is the internalization of the values, and the second is the assimilation of knowledge, abilities and skills necessary for a person to succeed in life.

Therefore, the importance of such processes in the University as: "educational activity" (figure 2), "leisure activity" (figure 3).

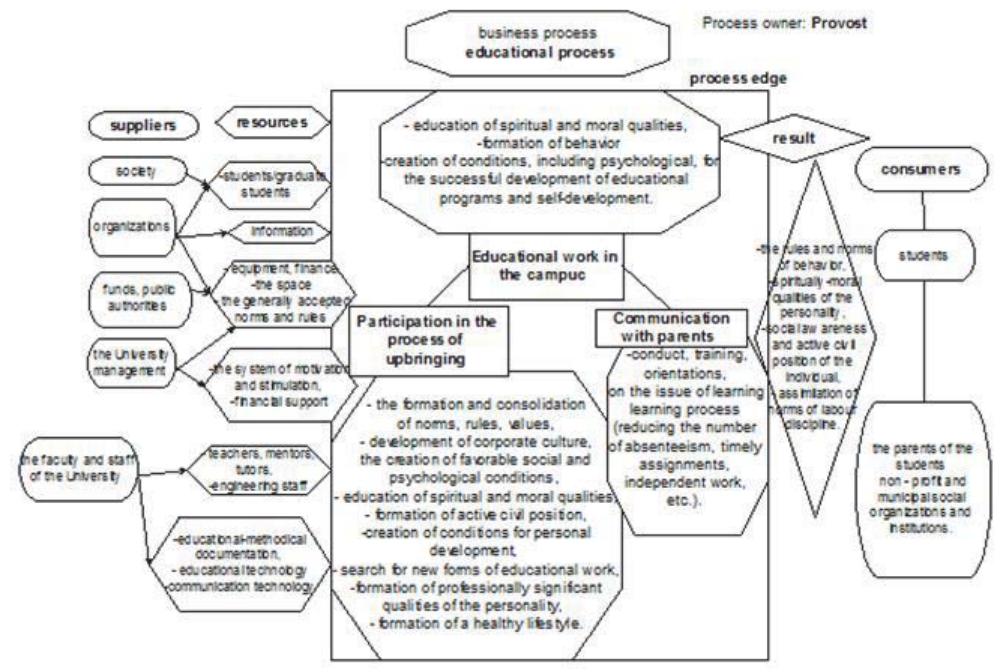

Figure 2. The model of the business process "Educational process" 


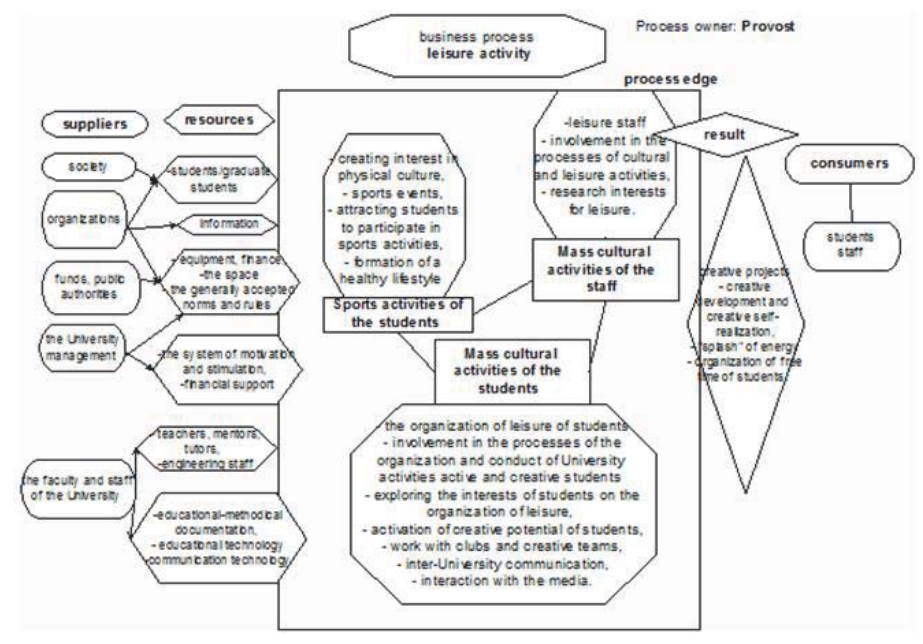

Figure 3. Model the organization of the "leisure activity" at the Universityln addition, a strategically important problem of modern education is the training and education of professionals able in conditions of rapidly developing technologies, have the ability to continuously improve my professional and intellectual level that has brought to the fore the concept of educational activity throughout a person's life. Figure 4 shows the process of "personality development and continuing education", which can be implemented within the framework of innovative development of the university and to solve the real problem.

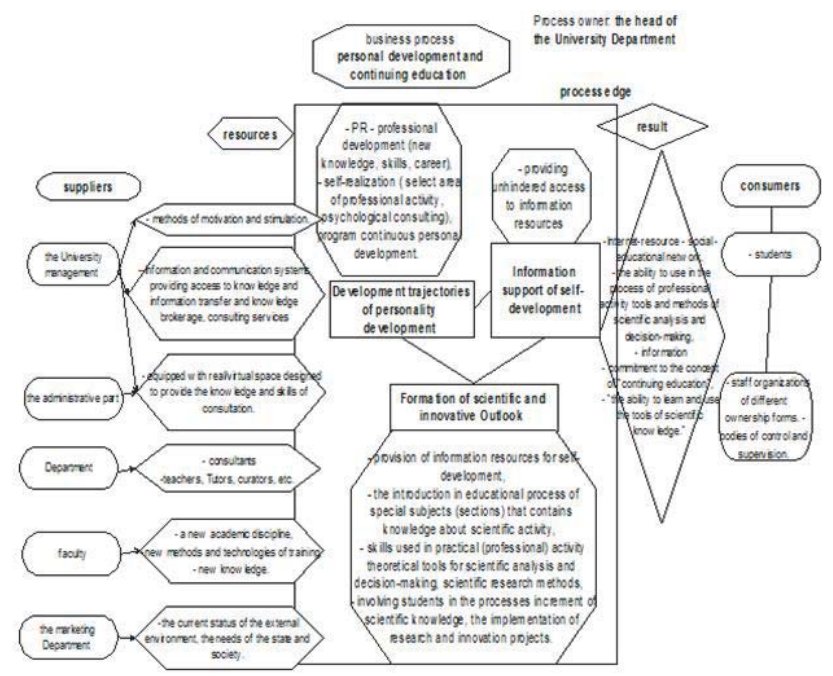

Figure 4. Model the organization of the "Personal development and continuing education"

Before modern higher school is strategically important task of bridging the gap between the level of education needed by workers and the fact that today actually gives the university. For entry into the knowledge society needs well-rounded people with interpersonal skills work, not requiring constant guidance, capable of functioning in conditions of uncertainty, to conduct an independent search solutions to complex problems included in the philosophy of continuing education. To resolve this problem, it is necessary to improve the quality of education, to interact with the real sector of the economy (figure 5). 


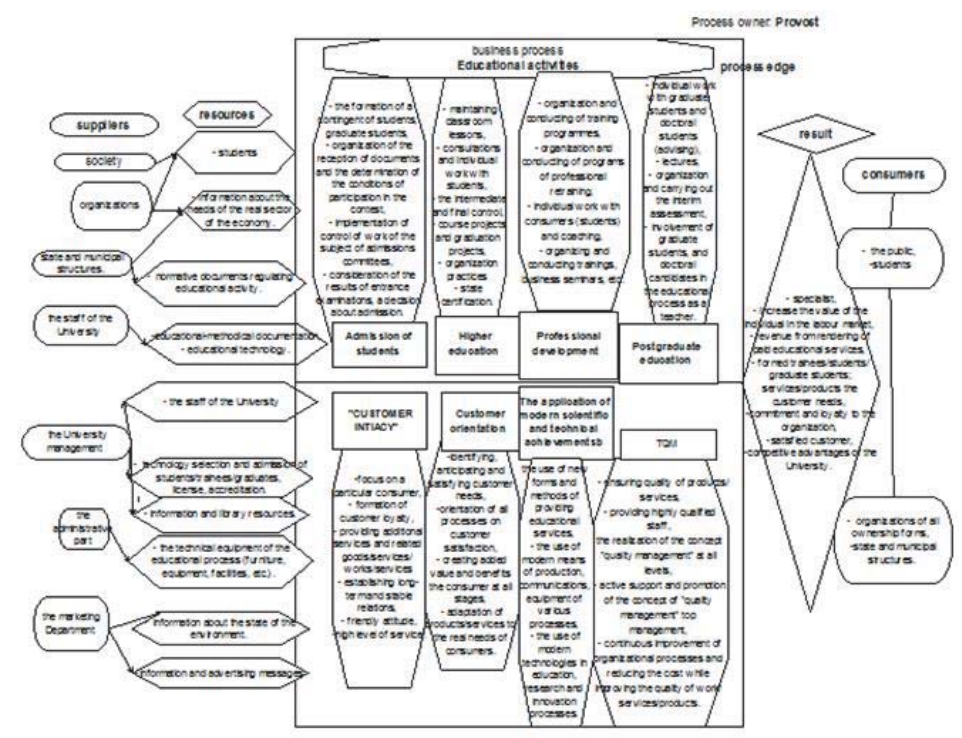

Figure 5. The model of the business process, "Educational activities"

Accordingly, in the solution of these important tasks needs consolidated efforts of the high school and the state.

\section{Conclusion}

State policy in the field of higher education should assume that the state Institute a long-term perspective and expect immediate results, implementation of those needs that are urgent "today and now" is not only impossible and illegal. It is important to understand that the socio-cultural environment of the University is already historically unique space, the ideal of a competitive environment, which allows you to "break up" not by social status, but at the expense of personal talents, abilities and desires be realized as a creative person, as a public figure or as a highly skilled production worker. Even in the highly unification of higher education in Soviet times, it was the University environment has become a springboard for the modern representatives of the Russian elite.

It is necessary to form youth intellectual and cultural intelligentsia as a stable social class, not in fragments "sprayed" on various social layers, and a self - aware class of people-as creators of the future of his country, widely distributed in all regions of Russia, able to make economic and scientific-technological growth of the country and decisively to defend its multinational culture.

A key role in the formation of youth elites in the modern world is given to the graduate school. Elite education, is able to provide strategically important branches of the economy development of high quality professionals, as well as shaping the political elite of the country, requires innovative approaches and continuous transformations to adapt under challenging conditions of the external environment. Such adaptation and the policy of innovative development of the higher school is able to ensure the sustainable competitiveness of systems for training youth elite in the University, to increase the efficiency of educational process, quality of training, as well as the rating of the educational system of the state.

Terms innovative development of higher education and the key factors in the successful implementation of the task of training personnel for the elite of the national economy can be considered educational, recreational, youth agencies, government agencies, implementing youth policy and ensures the formation and development of the national education system.

Presented in the paper model of the formation of the youth elite can be used:

- $\quad$ higher education institutions of the Russian Federation for the training of qualified personnel;

- state and community organizations at the local and regional levels in the implementation of youth policy. 


\section{References}

Bell, D. (1973). The Coming of Post-Industrial Society. New York: Basic Books.

Gaiduk, V.V. (2011). The political transformation of the status of regions in the conditions of modernization of Russian federalism. Journal the Issues of political science, 4, 90-91.

Giddens, A. (1990).The Consequences of Modernity. Stanford University Press.

GOST R ISO 9004-2001. The quality management system. Recommendations for improvement activities

Habermas, J. (1989). The Structural Transformation of the Public Sphere. Cambridge, MA: The MIT-press.

Kemple, T., Mawani, R. (2009). The Sociological Imagination and its Imperial Shadows. Journal: Theory Culture \& Society, 26 (7-8), 228249.

Kymlicka, W. (1990). Contemporary Political Philosophy: An Introduction. Oxford: Oxford University Press.

Lebedeva, N.A. (2014). A comprehensive system for monitoring of the factors of the external and internal environment of a higher educational institution. Journal of Creative Economy, 11 (95), 19-32.

Lukyantsev, A.S. (2014). Trend basis for the formation of image of the political leader of the federated Russia. Bulletin of the Bashkir Institute of social technologies, 3(24), 96- 97.

Outils pour une prospective des qualifications. (1996). Commissariat Général du Plan, La Documentation francaise.

Shuman, H., Scott, J. (1989). Generations and Collective Memories [Online] Available: http://isites.harvard.edu/fs/docs/icb.topic96263. files/generations_memories.pdf (July 17, 2015). 